\title{
A Multi-Index Feedback Linearization Control for a Buck-Boost Converter
}

\author{
Xiaocong $\mathrm{Li}^{1}$ and Xin Chen ${ }^{2, *(\mathbb{D})}$ \\ 1 Guangxi Key Laboratory of Power System Optimization and Energy Technology, Guangxi University, \\ Nanning 530004, China; lhtlht@gxu.edu.cn \\ 2 College of Electrical Engineering, Guangxi University, Nanning 530004, China \\ * Correspondence: 1812301005@st.gxu.edu.cn
}

check for updates

Citation: Li, X.; Chen, X. A MultiIndex Feedback Linearization Control for a Buck-Boost Converter. Energies 2021, 14, 1496. https://doi.org/ 10.3390/en14051496

Academic Editor: Gabriele Grandi

Received: 8 February 2021

Accepted: 5 March 2021

Published: 9 March 2021

Publisher's Note: MDPI stays neutral with regard to jurisdictional claims in published maps and institutional affiliations.

Copyright: (c) 2021 by the authors. Licensee MDPI, Basel, Switzerland. This article is an open access article distributed under the terms and conditions of the Creative Commons Attribution (CC BY) license (https:// creativecommons.org/licenses/by/ $4.0 /)$.

\begin{abstract}
Due to the nonlinear and nonminimum phase characteristics of the buck-boost converter, the design of its controller has always been a challenging problem. In this paper, a multi-index feedback linearization control strategy is proposed to design the controller of the buck-boost converter. Firstly, by constructing an appropriate output function, the original nonlinear system is mapped into a combination of a linear subsystem and a nonlinear subsystem. Then, according to the structural characteristics of these two subsystems, the linear optimal control theory is adopted for the control design of the linear subsystem to make it have a good output performance, while for the nonlinear subsystem, the coefficient of the output function is adjusted to ensure its stability. Finally, based on the Hartman-Grobman theorem, the internal mechanism and coefficient adjustment basis of the proposed method are revealed; that is, by adjusting the coefficient of the output function and the feedback coefficient of the linear control law, the poles of the system are configured to achieve the purpose of adjusting the static and dynamic performance of the system. The simulation results show the feasibility and superiority of using the multi-index feedback linearization control strategy to design the nonlinear control law of the buck-boost converter.
\end{abstract}

Keywords: buck-boost converter; multi-index; feedback linearization; output function; linear subsystem; nonlinear subsystem; pole assignment

\section{Introduction}

The buck-boost converter is a kind of common power electronic converter, which has the characteristics of step-up or step-down, simple structure, and easy grounding [1-3]. Therefore, it is widely used in social applications, such as solar power [4-6], battery technology $[7,8]$, vehicles [9,10], light emitting diode (LED)lamp driver [11], and telecommunication equipment [12]. However, the buck-boost converter is a typical nonminimum phase system, where when the output voltage is taken as the control input, its approximate linear system will have the system zeros on the right half of the s-plane, which leads to system instability and brings great difficulties to the controller design of the converter [13]. Furthermore, due to the influence of nonlinear characteristics, the dynamic process of the buck-boost converter is more complex, such that the design of the controller often needs to limit the closed-loop bandwidth to ensure the stability of the system [14]. Therefore, the controller design of the buck-boost converter has always been a challenging problem.

Many scholars are devoted to the control research of the buck-boost converter. For example, the traditional double closed-loop PI control method [15] is used to design the controller of the buck-boost converter, which does not need the predictive system model, and is easy to be implemented in engineering practice. However, its dynamic performance is general. The fuzzy control method in [16] can make the buck-boost converter have a stable output voltage without accurate system parameters. However, this method is not suitable for engineering applications, because its implementation may be too expensive. The sliding mode control method in [17] can better solve the nonlinear characteristics of 
the buck-boost converter, realizing the fast tracking of output voltage, and making the controlled system have strong robustness, but this method has the problem of output voltage chatter. On this basis, the PI and sliding mode control (PI-SMC) method was proposed in [13], where through selection of the appropriate PI gain and combination with sliding mode control, the buck-boost converter has good voltage tracking performance and strong robustness. However, the introduction of sliding mode control will still cause output voltage chatter. There are other modern, optimal, and/or nonlinear control methodologies for the control of the buck-boost converter, such as gain-scheduled control [18], passivitybased control [19], robust linear control [20], and model predictive control (MPC) [21,22]. In this paper, a novel nonlinear control method based on the feedback linearization theory is proposed to solve the problems of nonlinear and nonminimum phase characteristics.

The core of the feedback linearization theory is to find a suitable nonlinear coordinate transformation to transform a nonlinear system into a linear system [23]. The authors of [24] showed that the linear optimal control design of the converted linear system can make the original nonlinear system have optimal control performance. This means that the control problem of the nonlinear system can be transformed into that of the linear system, greatly reducing the difficulty of the controller design. Meanwhile, it was found in [25] that when the selected transformation satisfies certain conditions, a nonminimum phase system can be transformed into a minimum phase system. Therefore, theoretically, the feedback linearization theory is one of the most suitable theories to solve the controller design problem of the buck-boost converter. However, not all nonlinear systems can be linearized into a linear system by feedback, which needs complex operation proof [24]. Nevertheless, the feedback linearization theory is still widely used in the power system [26-29], power electronics $[30,31]$, chemical industry $[32,33]$, vehicles $[34,35]$, and aerospace $[36,37]$.

In view of the limitation of the feedback linearization design theory, a multi-index feedback linearization control strategy based on feedback linearization is proposed in this paper, where it does not require the complete exact linearization of the nonlinear system, and a simple and effective selection method of the output function is proposed [38]. In this method, the linear combination of the concerned state variables is taken as the output function, such that the original nonlinear system is transformed into a combination of a linear subsystem and a nonlinear subsystem. The choice of the output function is very important. This is because the dynamic behavior of the state variables selected into the output function will be effectively constrained to achieve the control of multiple indicators. By deduction, the paper reveals the essence of the multi-index feedback linearization control method, which reallocates the poles of the control system by adjusting the coefficients of the output function and the feedback coefficients of the linear control law, so as to control the stability and dynamic performance of the system.

\section{The Model of the Buck-Boost Converter}

The buck-boost converter is mainly composed of an input power supply E, a MOSFET switch S, a switching diode D, an input inductor L, an output capacitor C, and a load resistor R (see Figure 1).

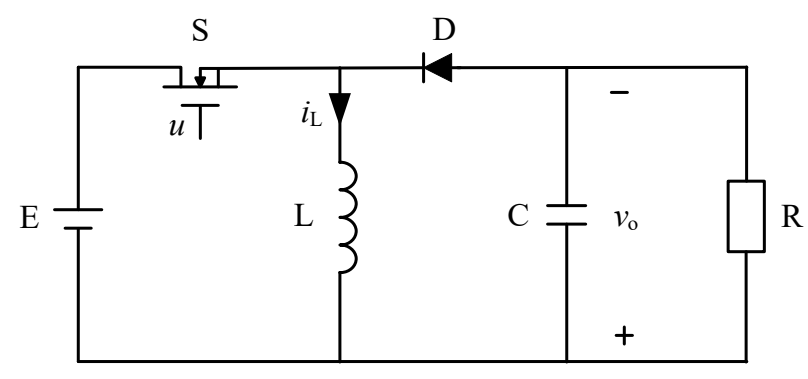

Figure 1. Circuit structure of the buck-boost converter. 
We will briefly introduce the working principle of the buck-boost converter. In the continuous conduction mode, when $u=1$, the equivalent circuit of the converter is shown in Figure 2. The circuit structure of the buck-boost converter can be regarded as two circuits, where for the first circuit, the input power is directly applied to both ends of the input inductor to charge the input inductor, and for the other circuit, the output capacitor releases energy to the load resistor. When $u=0$, the equivalent circuit of the converter is shown in Figure 3. The current direction of the input inductor remains unchanged due to the inductance-induced electric potential, and the energy stored in the inductor will be transferred to the output capacitor and load resistor to realize the energy transfer from the input power to the output voltage.

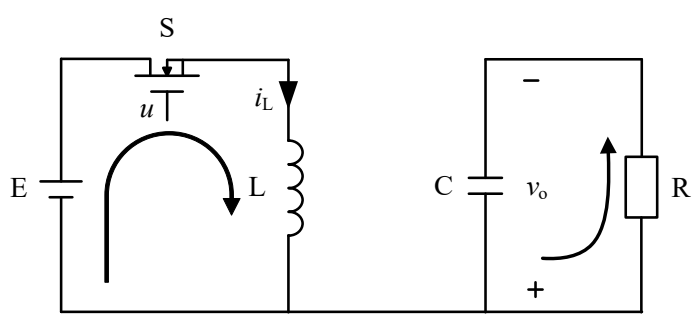

Figure 2. The equivalent circuit of the buck-boost converter when $u=1$.

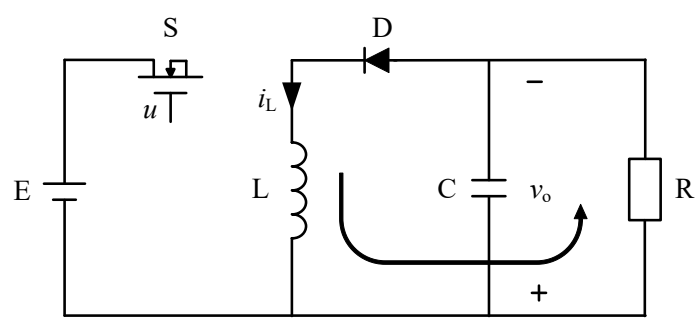

Figure 3. The equivalent circuit of the buck-boost converter when $u=0$.

According to the state space averaging method, when $u=1$, the state differential equation of the circuit can be written as follows:

$$
\left\{\begin{array}{l}
\dot{i}_{\mathrm{L}}=\frac{E}{L} \\
\dot{v}_{\mathrm{O}}=-\frac{v_{\mathrm{o}}}{\mathrm{C} R}
\end{array}\right.
$$

where $i_{\mathrm{L}}$ and $v_{\mathrm{O}}$ represent the input inductance current and output capacitor voltage, respectively; $E$ represents the input power supply voltage.

When $u=0$, the state differential equation of the circuit can be written as follows:

$$
\left\{\begin{array}{l}
\dot{i}_{\mathrm{L}}=-\frac{v_{\mathrm{O}}}{L} \\
\dot{v}_{\mathrm{O}}=\frac{R i_{\mathrm{L}}-v_{\mathrm{o}}}{C R}
\end{array}\right.
$$

Therefore, in the continuous conduction mode, the average state equation of the buck-boost converter can be written as follows:

$$
\left\{\begin{array}{l}
\left\{\begin{array}{l}
\dot{i}_{\mathrm{L}}=\frac{E}{L} u-\frac{1-u}{L} v_{\mathrm{O}} \\
\dot{v}_{\mathrm{O}}=\frac{1-u}{C} i_{\mathrm{L}}-\frac{1}{C R} v_{\mathrm{O}}
\end{array}\right. \\
y=h\left(i_{\mathrm{L}}, v_{0}\right)
\end{array}\right.
$$

where $u$ represents the input control variable of the system, i.e., the duty cycle of the switch; $y$ is the output function; and $h\left(i_{\mathrm{L}}, v_{\mathrm{O}}\right)$ is a scalar function. 


\section{The Multi-Index Feedback Linearization Control Method}

\subsection{Design Idea of the Multi-Index Feedback Linearization Control}

Consider an affine single input single output nonlinear control system:

$$
\left\{\begin{array}{l}
\dot{x}=f(x)+g(x) u \\
y=h(x)
\end{array}\right.
$$

where $x=\left[x_{1}, \ldots, x_{n}\right]^{\mathrm{T}}$ is the state vector of the system; $f(x)$ and $g(x)$ are two $n$-dimensional smooth vector fields; $u$ is the control scalar; $y$ is the output variable; and $h(x)$ is a scalar function.

Definition 1. If there is a field $U$ of $x$ and a positive integer $r$ satisfy the following equation:

$$
\left\{\begin{array}{l}
L_{g} L_{f}^{k} h(x) \equiv 0, \forall x \in U, 0 \leq k \leq r-2 \\
L_{g} L_{f}^{k} h(x) \neq 0, k=r-1
\end{array}\right.
$$

then the relative order of the output function $h(x)$ with respect to the system is $r$.

Here, $L_{f}^{k} h(x)$ is the $k$-order Lie derivative of $h(x)$ to $f(x)$ and $L_{g} L_{f}^{k} h(x)$ is the Lie derivative of $L_{f}^{k} h(x)$ to $g(x)$. When the relative order $r$ is equal to the order $n$ of the system, the system can be linearized exactly.

According to (5), it can be seen that the selection of the output function is very important, in which different output functions will have different relative orders with the system. For many nonlinear systems, it is difficult to find the output function making the relative order equal to the order of the system. Therefore, this paper proposes a new method to select the output function, where the system can achieve good control performance without complete accurate linearization. The output function is selected in the form of equation:

$$
y=c x
$$

where $c$ is the coefficient vector of the output function, and for the state variables that do not need to be selected into the output function, the corresponding coefficients are taken as zero.

The $k$ derivative of the output function $y$ can be written as follows:

$$
y^{(k)}=L_{f}^{k} h(x)+L_{g} L_{f}^{k-1} h(x) u, k=0,1, \cdots, r
$$

Substituting (5) into (7), we can get:

$$
\left\{\begin{array}{l}
y^{(k)}=L_{f}^{k} h(x), k=0,1, \cdots, r-1 \\
y^{(r)}=L_{f}^{r} h(x)+L_{g} L_{f}^{r-1} h(x) u, k=r
\end{array}\right.
$$

According to the structural characteristic of (8), the nonlinear coordinate transformation can be selected as follows:

$$
z=\left[\begin{array}{l}
z_{1} \\
z_{2} \\
\vdots \\
z_{r} \\
z_{r+1} \\
\vdots \\
z_{n}
\end{array}\right]=\left[\begin{array}{l}
y \\
\dot{y} \\
\vdots \\
y^{r-1} \\
\eta_{1} \\
\vdots \\
\eta_{n-r}
\end{array}\right]=\left[\begin{array}{l}
h(x) \\
L_{f} h(x) \\
\vdots \\
L_{f}^{r-1} h(x) \\
\eta_{1}(x) \\
\vdots \\
\eta_{n-r}(x)
\end{array}\right]=\Phi(x)
$$

where $z$ is a new state vector and $\eta$ is a function of $x$. The selection of $\eta$ must satisfy the requirement that the rank of Jacobian matrix $\partial \Phi(x) / \partial x$ is equal to the order of the system, 
so as to ensure that the selected nonlinear coordinate transformation is a local differential homeomorphism transformation.

Therefore, the original nonlinear system (4) can be transformed into a partially accurate linearized system by nonlinear transformation (9):

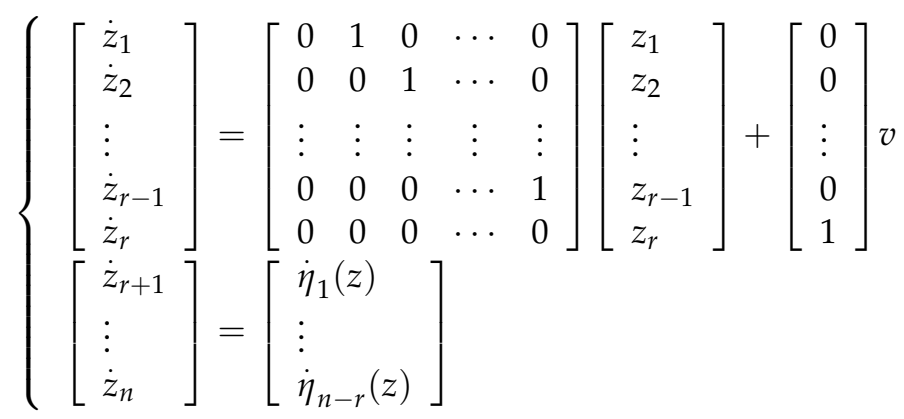

where $z_{\mathrm{L}}=\left[z_{1}, \ldots, z_{r}\right]^{\mathrm{T}}$ is the state vector of the linear subsystem; $z_{\mathrm{N}}=\left[z_{r+1}, \ldots, z_{n}\right]^{\mathrm{T}}$ is the state vector of the nonlinear subsystem; and $v=L_{f}^{r} h\left[\Phi^{-1}(z)\right]+L_{g} L^{r-1} f h\left[\Phi^{-1}(z)\right] u$ is the control law of the linear subsystem.

According to the structure of (10), it can be seen that the state vector $\left(z_{\mathrm{L}}\right)$ of the linear subsystem can affect the nonlinear subsystem, while the state vector $\left(z_{\mathrm{N}}\right)$ of the nonlinear subsystem cannot affect the linear subsystem. Since the output of the original nonlinear system is only related to the linear subsystem $\left(y=z_{1}\right)$, it can be concluded that if we want to make the original nonlinear system stable and have good performance, we only need to make the nonlinear subsystem asymptotically stable and make the linear subsystem realize linear optimization. According to this idea, we can design the nonlinear control law of the original nonlinear system.

\subsection{Solution of the Multi-Index Feedback Linearization Control Law}

Based on the above analysis, we need to study the influence of the linear subsystem and nonlinear subsystem on the original system, and finally obtain the nonlinear control law of the original nonlinear system

First of all, for the linear subsystem, the linear subsystem of (10) is designed by using the linear optimal control theory, in which the quadratic performance index:

$$
J=\frac{1}{2} \int_{0}^{\infty}\left(z_{L}^{\mathrm{T}} Q z_{L}+v^{\mathrm{T}} R v\right) d t
$$

where $Q$ is a positive definite or semi-positive definite $r \times r$ weight matrix; $R$ is a positive definite $1 \times 1$ weight matrix.

Solving the Riccati equation:

$$
A^{\mathrm{T}} \boldsymbol{P}+\boldsymbol{P A}-\boldsymbol{P} \boldsymbol{b} \boldsymbol{R}^{-1} \boldsymbol{b}^{\mathrm{T}} \boldsymbol{P}+\boldsymbol{Q}=0
$$

where $A$ is the $r \times r$ state matrix of the system; $\boldsymbol{b}$ is the $r \times 1$ control matrix of the system; and $\boldsymbol{P}$ is the solution of the Riccati equation.

The control law of the linear subsystem can be obtained as follows:

$$
v=-\boldsymbol{R}^{-1} \boldsymbol{b}^{\mathrm{T}} \boldsymbol{P} z_{L}=-\boldsymbol{k} \boldsymbol{z}_{L}=-k_{1} z_{1}-k_{2} z_{2} \cdots-k_{r} z_{r}
$$

where $k_{1}, \ldots, k_{r}$ is the feedback coefficients of the linear control law.

By adjusting the feedback coefficients of the linear control law, the linear subsystem can be asymptotically stable, and then combining with (10), we can get:

$$
\dot{z}_{L}=0 \Rightarrow z_{L}=0 \Rightarrow y(\infty)=0
$$


In conclusion, the optimal output performance of the system can be obtained by properly adjusting the feedback coefficient of the linear control law.

Secondly, for the nonlinear subsystem, when the linear subsystem enters the steady state, the dynamic system (also known as the zero dynamic system) composed of nonlinear subsystems can be written as follows:

$$
\left\{\begin{array}{l}
\dot{z}_{r+1}=\dot{\eta}_{1}\left(0, z_{N}\right) \\
\vdots \\
\dot{z}_{n}=\dot{\eta}_{n-r}\left(0, z_{N}\right)
\end{array}\right.
$$

If the dynamic system (15) is stable, the system (10) is also stable [19]. If the zero dynamic system cannot be asymptotically stable, the nonlinear mapping relation derived from the selected output function cannot meet the stability requirements of the system, so the output function needs to be reconstructed.

Through the stability analysis of the zero dynamic system in Section 5, we can know that adjusting the coefficient of the output function can make the system (15) tend to be asymptotically stable.

Therefore, we can draw a conclusion that by adjusting the feedback coefficient of the linear control law and the coefficient of the output function, the original system can have the optimal control performance and good stability.

Finally, combining (8), (9), (10), and (13), the nonlinear control law of the original nonlinear system can be obtained as follows:

$$
u=\frac{-L_{f}^{r} h\left[\Phi^{-1}(z)\right]-k z_{L}}{L_{g} L_{f}^{r-1} h\left[\Phi^{-1}(z)\right]}=\frac{-L_{f}^{r} h(x)-\left(k_{1} h(x)+k_{2} L_{f}^{1} h(x)+\cdots+k_{r} L_{f}^{r-1} h(x)\right)}{L_{g} L_{f}^{r-1} h(x)}
$$

So far, the design of the multi-index feedback linearization control method of the system (4) is completed. It is worth noting that this design method transforms the original nonlinear system into a linear subsystem and a nonlinear subsystem through nonlinear coordinate transformation, which still keeps a one-to-one correspondence relationship. Therefore, under the effect of this control method, the state information of the original system is not lost at all, so the system obtained by the transformation can accurately reflect the state of the original system.

\section{Mechanism Analysis of the Multi-Index Feedback Linearization Control for the Buck-Boost Converter}

As we all know, the linear system is a special case of the nonlinear system, so the multi-index feedback linearization control method can also be applied to the linear system. By analyzing the operation mechanism of the proposed control method in the linear system, and with the help of Hartman-Grobman theorem, the internal operation principle of the proposed control method in the nonlinear system can be deduced.

Theorem 1. Hartman-Grobman theorem: Let $x_{0}$ be the hyperbolic singularity of the nonlinear system, then there is a neighborhood $U$ of $x_{0}$ such that the nonlinear system and its first approximation system are topologically equivalent in this neighborhood $U$.

The Hartman-Grobman theorem is an important bridge between nonlinear control methods and linear control methods: the trajectories near hyperbolic singularities of nonlinear systems can be mapped onto the trajectories of their first approximation systems through a bijective continuous mapping [38]. 


\subsection{Approximate Linear Model of the Buck-Boost Converter}

The system (3) is expanded by Taylor series at the equilibrium point, let $x_{\mathrm{e}}=\left[x_{1 \mathrm{e}}, x_{2 \mathrm{e}}\right]^{\mathrm{T}}$ $=\left[i_{\mathrm{Le}}, v_{\mathrm{oe}}\right]^{\mathrm{T}}$, and its first-order approximate linear system can be obtained as follows:

$$
\left\{\begin{array}{l}
{\left[\begin{array}{l}
\dot{x}_{1 \mathrm{e}} \\
\dot{x}_{2 \mathrm{e}}
\end{array}\right]=\left[\begin{array}{cc}
0 & \frac{u_{0}-1}{L} \\
\frac{1-u_{0}}{C} & -\frac{1}{C R}
\end{array}\right]\left[\begin{array}{l}
x_{1 \mathrm{e}} \\
x_{2 \mathrm{e}}
\end{array}\right]+\left[\begin{array}{c}
\frac{E+x_{20}}{L} \\
-\frac{x_{10}}{C}
\end{array}\right] u} \\
y=h\left(x_{1 \mathrm{e}}, x_{2 \mathrm{e}}\right)
\end{array}\right.
$$

where $x_{10}=u_{0} E /\left[\left(u_{0}-1\right)^{2} R\right], x_{20}=u_{0} E /\left(1-u_{0}\right)$, and $u_{0}$ are the input current value, the output voltage value, and the control quantity at the equilibrium point, respectively.

Taking the linear transformation $x=T_{\mathrm{cs}} x_{\mathrm{e}}$, the system (17) can be transformed into a controllable standard system:

$$
\left[\begin{array}{l}
\dot{x}_{1} \\
\dot{x}_{2}
\end{array}\right]=\left[\begin{array}{cc}
0 & 1 \\
-a_{1} & -a_{2}
\end{array}\right]\left[\begin{array}{l}
x_{1} \\
x_{2}
\end{array}\right]+\left[\begin{array}{l}
0 \\
1
\end{array}\right] u
$$

where $a_{1}=-\left(1-u_{0}\right)^{2} /(L C)$ and $a_{2}=1 /(C R)$.

The system (18) can be abbreviated as follows:

$$
\dot{x}=A x+b u
$$

Through the linear transformation $x=T_{\mathrm{cs}} x_{\mathrm{e}}$, the corresponding output function of the system (19) can be written as follows:

$$
y=c_{s} x
$$

where $c_{\mathrm{s}}=\boldsymbol{c} \boldsymbol{T}_{\mathrm{cs}}{ }^{-1}=\left[\begin{array}{cc}c_{\mathrm{s} 1} & c_{\mathrm{s} 2}\end{array}\right] ; c$ is the coefficient vector of the original output function. tem (19):

Equations (9), (10), (13), and (16) are combined to obtain the control law of the sys-

$$
\begin{aligned}
& u=\frac{-L_{f}^{1} h(\boldsymbol{x})-k_{1} z_{1}}{L_{g} L_{f}^{0} h(\boldsymbol{x})}=\frac{-L_{f}^{1}\left(\boldsymbol{c}_{s} \boldsymbol{x}\right)-k_{1} \boldsymbol{c}_{S} \boldsymbol{x}}{L_{g}\left(\boldsymbol{c}_{s} \boldsymbol{x}\right)}=\frac{-\boldsymbol{c}_{S} \boldsymbol{A}^{1} \boldsymbol{x}+v}{\boldsymbol{c}_{s} \boldsymbol{b}} \\
& =-\left(\boldsymbol{c}_{S} \boldsymbol{b}\right)^{-1} \cdot \boldsymbol{c}_{S} \boldsymbol{A}^{1} \boldsymbol{x}-\left(\boldsymbol{c}_{S} \boldsymbol{b}\right)^{-1} \boldsymbol{k} \boldsymbol{K} \boldsymbol{x}=-\boldsymbol{k}_{N} \boldsymbol{x}-\boldsymbol{k}_{\mathrm{L}} \boldsymbol{x}
\end{aligned}
$$

where $v=k \boldsymbol{K} x, \boldsymbol{k}_{\mathrm{N}}=\left(\boldsymbol{c}_{\mathrm{s}} \boldsymbol{b}\right)^{-1} \boldsymbol{c}_{\mathrm{S}} \boldsymbol{A}^{1}, \boldsymbol{k}_{\mathrm{L}}=\left(\boldsymbol{c}_{\mathrm{s}} \boldsymbol{b}\right)^{-1} \boldsymbol{k} \boldsymbol{K}, \boldsymbol{k}=\left[k_{1}\right]$, and $\boldsymbol{K}=\left[\boldsymbol{c}_{\mathrm{s}}^{\mathrm{T}}\right]^{\mathrm{T}}$.

Substituting (21) into (19), the feedback closed-loop control system can be obtained as follows:

$$
\dot{x}=\left(\boldsymbol{A}-\boldsymbol{b} \boldsymbol{k}_{\mathrm{N}}-\boldsymbol{b} \boldsymbol{k}_{\mathrm{L}}\right) \boldsymbol{x}=\left(\boldsymbol{A}_{\mathrm{N}}-\boldsymbol{b} \boldsymbol{k}_{\mathrm{L}}\right) \boldsymbol{x}=\boldsymbol{A}_{\mathrm{NL}} \boldsymbol{x}
$$

where $A_{\mathrm{NL}}=A_{\mathrm{N}}-\boldsymbol{b} \boldsymbol{k}_{\mathrm{L}}$ is the state matrix of the feedback closed-loop system; $\boldsymbol{A}_{\mathrm{N}}=\boldsymbol{A}-\boldsymbol{b} \boldsymbol{k}_{\mathrm{N}}$ is a matrix symbol, which is introduced for the convenience of the following analysis.

\subsection{Pole Assignment Principle}

By analyzing the relationship between the output function coefficient, the feedback coefficient of the control law, and the eigenvalues of the system (22), the internal operation mechanism of the multi-index feedback linearization control method is revealed.

For matrix $A_{\mathrm{N}}$ :

$$
A_{\mathrm{N}}=A-\boldsymbol{b} \boldsymbol{k}_{\mathrm{N}}=\boldsymbol{A}-\boldsymbol{b}\left(\boldsymbol{c}_{\mathrm{s}} \boldsymbol{b}\right)^{-1} \boldsymbol{c}_{\mathrm{S}} A^{1}=\left[\begin{array}{cc}
0 & 1 \\
0 & -c_{\mathrm{s} 1} / c_{\mathrm{s} 2}
\end{array}\right]
$$

The characteristic polynomial of matrix $A_{\mathrm{N}}$ can be written as follows:

$$
\left(s+c_{\mathrm{s} 1} / c_{\mathrm{s} 2}\right) s=0
$$

It can be seen that through the feedback effect of the $\boldsymbol{b} \boldsymbol{k}_{\mathrm{N}}$ term, one pole of the system is assigned to the position determined by the output function coefficient, and the remaining pole is assigned to the origin. 
For matrix $A_{\mathrm{NL}}$ :

$$
\boldsymbol{A}_{\mathrm{NL}}=\boldsymbol{A}_{\mathrm{N}}-\boldsymbol{b} \boldsymbol{k}_{\mathrm{L}}=\boldsymbol{A}_{\mathrm{N}}-\boldsymbol{b}\left(\boldsymbol{c}_{\mathrm{s}} \boldsymbol{b}\right)^{-1} \boldsymbol{k} \boldsymbol{K}=\left[\begin{array}{lc}
0 & 1 \\
-k_{1} c_{\mathrm{s} 1} / c_{\mathrm{s} 2} & -\left(c_{\mathrm{s} 1}+k_{1} c_{\mathrm{s} 2}\right) / c_{\mathrm{s} 2}
\end{array}\right]
$$

where:

$$
\boldsymbol{b}\left(\boldsymbol{c}_{\mathrm{s}} \boldsymbol{b}\right)^{-1} \boldsymbol{k} \boldsymbol{K}=\left[\begin{array}{lc}
0 & 0 \\
k_{1} c_{\mathrm{s} 1} / c_{\mathrm{s} 2} & k_{1}
\end{array}\right]
$$

The characteristic polynomial of matrix $A_{\mathrm{NL}}$ can be written as follows:

$$
\left(s+c_{\mathrm{s} 1} / c_{\mathrm{s} 2}\right)\left(s+k_{1}\right)=0
$$

It can be seen that on the basis of the feedback of the $\boldsymbol{b} \boldsymbol{k}_{\mathrm{N}}$ term, the remaining pole of the system is assigned to any position through the feedback of the $\boldsymbol{b} \boldsymbol{k}_{\mathrm{L}}$ term.

It can be seen from the above analysis that one pole of the system is assigned to the desired position by selecting the appropriate output function coefficients, and then the remaining pole is assigned to the desired position by selecting the appropriate feedback coefficients of the linear control law. According to the Hartman-Grobman theorem, it can be concluded that the essence of the control method proposed in this paper is that by adjusting the output function coefficients and the feedback coefficients of the linear control law, the system can realize pole assignment, further achieving the stability and dynamic performance of the system.

We can determine the position of the poles according to the performance requirements of the system design, and then determine the output function coefficient $\left(c_{\mathrm{s} 1}, c_{\mathrm{s} 2}\right)$ and the feedback coefficient $(k)$ by calculation (27). After $c_{\mathrm{s} 1}$ and $c_{\mathrm{s} 2}$ are obtained, the output function coefficient of the original system can be obtained by linear transformation $\left(c=c_{\mathrm{S}} T_{\mathrm{cs}}\right)$, and the feedback coefficient $k$ can be directly used in the original system without transformation [38].

\section{Multi-Index Feedback Linearization Control Design of the Buck-Boost Converter}

5.1. Design of the Control Law for the Buck-Boost Converter

The system (3) is reorganized to an affine nonlinear system:

$$
\left\{\begin{array}{l}
\left\{\begin{array}{l}
\dot{i}_{\mathrm{L}}=-\frac{1}{L} v_{\mathrm{O}}+\left(\frac{E+v_{\mathrm{O}}}{L}\right) u \\
\dot{v}_{\mathrm{O}}=\frac{1}{C} i_{\mathrm{L}}-\frac{1}{C R} v_{\mathrm{O}}-\frac{i_{\mathrm{L}}}{\mathrm{C}} u
\end{array}\right. \\
y=h\left(i_{\mathrm{L}}, v_{0}\right)
\end{array}\right.
$$

For the buck-boost converter, the output voltage is the most important state variable. Additionally, in order to improve the response speed of the output voltage, the input current should also be selected into the output function. This is because the control law including the input current can make the input power continuously charge the input inductor during the start-up period, and quickly transfer the energy of the input inductor to the output capacitor through the control switch, realizing the fast response of the output voltage. Therefore, the output function of the buck-boost converter can be written as follows:

$$
y=c_{1} \Delta i_{\mathrm{L}}+c_{2} \Delta v_{o}=z_{1}
$$

where $\Delta i_{\mathrm{L}}=i_{\mathrm{L}}-i_{\mathrm{Lr}}$ and $\Delta v_{\mathrm{O}}=v_{\mathrm{O}}-v_{\mathrm{or}} ; i_{\mathrm{Lr}}$ is the reference value of the input current; $v_{\text {or }}$ is the reference value of the output voltage; and $c_{1}$ and $c_{2}$ are the coefficients of the output function. Obviously, the relative order $r$ of the output function (29) to the system is 1, so we need to choose another transformation function $\left(\eta=v_{0}\right)$ to form the required nonlinear transformation:

$$
z=\left[\begin{array}{l}
z_{1} \\
z_{2}
\end{array}\right]=\left[\begin{array}{l}
c_{1} \Delta i_{\mathrm{L}}+c_{2} \Delta v_{\mathrm{o}} \\
v_{\mathrm{o}}
\end{array}\right]
$$


where when $c_{1} \neq 0$, the rank of Jacobian matrix of the nonlinear transformation is equal to 2. Therefore, the selected nonlinear coordinate transformation (30) is a local differential homeomorphism transformation.

Under the action of nonlinear transformation (30), we can obtain the following new system in $z$ state space:

$$
\left\{\begin{array}{l}
\dot{z}_{1}=c_{1}\left(\frac{E u}{L}-\frac{1-u}{L} z_{2}\right)+c_{2}\left(\frac{1-u}{C} z_{\mathrm{A}}-\frac{z_{2}}{C R}\right)=v \\
\dot{z}_{2}=\frac{1-u}{C} z_{\mathrm{A}}-\frac{z_{2}}{C R}
\end{array}\right.
$$

where $v$ is the control law of the linear subsystem; $z_{\mathrm{A}}=z_{1} / c_{1}-c_{2} z_{2} / c_{1}+c_{2} v_{\mathrm{or}} / c_{1}+i_{\mathrm{Lr}}$.

The system (31) can be abbreviated as:

$$
\left\{\begin{array}{l}
{\left[\dot{z}_{1}\right]=[0]\left[z_{1}\right]+[1] v} \\
{\left[\dot{z}_{2}\right]=[\dot{\eta}(z)]}
\end{array}\right.
$$

According to the linear optimal control theory, we can get $v=-k_{1}\left(c_{1} \Delta i_{\mathrm{L}}+c_{2} \Delta v_{\mathrm{o}}\right)$.

Equations (28), (30), and (31) are combined to obtain the control law of the buck-boost converter:

$$
u=\left(v+\frac{c_{1} v_{\mathrm{O}}}{L}-\frac{c_{2} i_{\mathrm{L}}}{C}+\frac{c_{2} v_{\mathrm{o}}}{C R}\right)\left(\frac{c_{1} E}{L}+\frac{c_{1} v_{\mathrm{o}}}{L}-\frac{c_{2} i_{\mathrm{L}}}{C}\right)^{-1}
$$

It can be seen from (33) that the multi-index feedback linearization control method can quickly solve the control law that possesses a simple structure, and it is easy to design and realize the controller. Figure 4 shows the closed-loop control flow of the buck-boost converter.

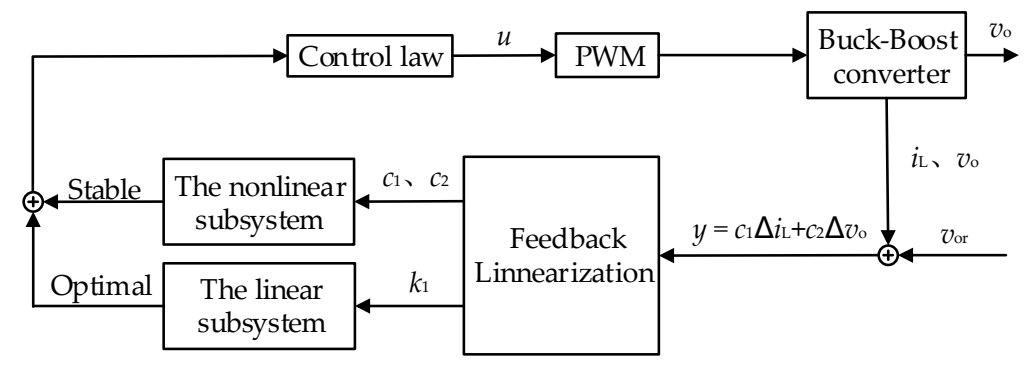

Figure 4. Closed-loop control of the buck-boost converter.

\subsection{Analysis of Zero Dynamic Stability of the Buck-Boost Converter}

For the system (31), let $\dot{z}_{1}=0$ and $z_{1}=0$, the control law can be obtained as follows:

$$
u\left(0, z_{2}\right)=\left(\frac{c_{1} z_{2}}{L}-\frac{c_{2} z_{\mathrm{B}}}{C}+\frac{c_{2} z_{2}}{C R}\right)\left(\frac{c_{1} E}{L}+\frac{c_{1} z_{2}}{L}-\frac{c_{2} z_{\mathrm{B}}}{C}\right)^{-1}
$$

where $z_{\mathrm{B}}=-c_{2} z_{2} / c_{1}+c_{2} v_{\mathrm{or}} / c_{1}+i_{\mathrm{Lr}}$.

Substituting (34) into (31), and making $z_{1}=0$, the zero-dynamic equation can be obtained as follows:

$$
\dot{z}_{2}=\frac{z_{\mathrm{B}}}{C}-\frac{z_{2}}{C R}-\left(\frac{c_{1} z_{2}}{L}-\frac{c_{2} z_{\mathrm{B}}}{C}+\frac{c_{2} z_{2}}{C R}\right)\left(c_{1} C E / L+c_{1} z_{2} C / L-c_{2} z_{\mathrm{B}}\right)^{-1}
$$

From the zero-dynamic Equation (35), it is important to note that the coefficients $c_{1}$ and $c_{2}$ of the output function affect the stability of the zero-dynamic equation. Therefore, it can be considered that the zero-dynamic equation can be stabilized by properly adjusting the values of $c_{1}$ and $c_{2}$, achieving the zero-dynamic stability of the system. 


\section{Simulation Analysis}

In order to verify the feasibility and effectiveness of the proposed control method, the simulation model of the buck-boost converter was established on the. MATLAB/Simulink platform. In the simulation experiment, the multi-index feedback linearization control method (MFLC) was compared with the traditional double closed-loop PI control method (PI) to highlight the superiority and practicability of the proposed control method. The main parameters of the buck-boost converter were: $E=15 \mathrm{~V}, R=30 \Omega, L=1 \mathrm{mH}, C=200 \mu \mathrm{F}$. At steady state, $u=4 / 7, f_{\mathrm{s}}=50 \mathrm{kHz}, i_{\mathrm{L}}=14 / 9 \mathrm{~A}, v_{\mathrm{O}}=20 \mathrm{~V}$, and $v_{\text {or }}=20 \mathrm{~V}$. According to the analysis of Section 4, the MFLC parameters can be selected as: $c_{1}=4,000,000$, $c_{2}=100,000$, and $k_{1}=40,000$, so the poles of the system were assigned to the following positions $\left(s_{1}=-432\right.$ and $\left.s_{2}=-40,000\right)$, satisfying the requirements of stable operation of the system. It is important to note that there is a big difference between the two poles such that $s_{1}$ is the dominant pole, i.e., the system can be regarded as a first order system, which was verified in the transient waveform of the output voltage of the following simulation experiment. The PI parameters were selected as: $k_{\mathrm{cp}}=2.66, k_{\mathrm{ci}}=600$ and $k_{\mathrm{vp}}=0.1, k_{\mathrm{vi}}=100$, respectively. The experiment was carried out from the following three aspects:

- $\quad$ Step change of the input voltage $E$;

- $\quad$ Step change of the load resistance $R$;

- Step change of the reference voltage $v_{\text {or }}$.

\subsection{Step Change of the Input Voltage $E$}

When the input voltage changes, whether the output voltage can quickly stabilize at the given reference voltage value is an important indicator of the superiority of the control method. When the input voltage $E$ changes suddenly, the response curves of the output voltage and the input current of the buck-boost converter are shown in Figure 5. At $0.07 \mathrm{~s}$, the input voltage $E$ steps from 15 to $24 \mathrm{~V}$; at $0.14 \mathrm{~s}$, the input voltage $E$ steps from 24 to $15 \mathrm{~V}$. It can be seen from Figure $5 \mathrm{a}$ that when the input voltage changes, under the action of MFLC, the output voltage is always stable at the given reference value of $20 \mathrm{~V}$, where its transient time and overshoot is $10 \mathrm{~ms}$ and $0.1 \mathrm{~V}$, respectively. By comparison, the output voltage under the traditional double closed-loop PI control can also be stable at the given reference value, but its dynamic process is general, i.e., its transient time and overshoot is $25 \mathrm{~ms}$ and $2 \mathrm{~V}$, respectively, which is far from the control performance of MFLC. Furthermore, it can be seen from Figure $5 b$ that under the action of MFLC, the starting overshoot value of the input current is only one-third of that under the action of PI. Additionally, when the input voltage changes, the input current value under the action of MFLC almost has no transient process, realizing the stability of the input current quickly. However, the input current under PI control needs a certain time to stabilize, which reflects the advantages of the multi-index feedback linearization control method.

\subsection{Step Change of the Load Resistance $R$}

Figure 6 shows the response curves of the output voltage and the input current of the buck-boost converter when the load resistance $R$ changes suddenly. At $0.07 \mathrm{~s}$, the load resistance $R$ decreases from 30 to $15 \Omega$; at $0.14 \mathrm{~s}$, the load resistance $R$ increases from 15 to $30 \Omega$. It can be seen from Figure $6 a$ that both control methods can stabilize the output voltage at a given reference value of $20 \mathrm{~V}$. However, the output voltage under MFLC has better dynamic performance compared with the PI control. In the start-up phase, the output voltage enters the steady state at $0.02 \mathrm{~s}$ without overshoot, while the output voltage under the PI control has an overshoot of $2.5 \mathrm{~V}$. Furthermore, when the load resistance changes, unlike the output voltage (PI) whose transient time and overshoot is $25 \mathrm{~ms}$ and $4 \mathrm{~V}$, respectively, the transient performance of output voltage (MFLC) is excellent, i.e., the transient time and overshoot is $10 \mathrm{~ms}$ and $0.75 \mathrm{~V}$, respectively. Therefore, compared with the PI control method, the MFLC method has better performance when the load resistance changes. Additionally, it can be seen from Figure $6 \mathrm{~b}$ that the input current $i_{\mathrm{L}}$ under the 
action of MFLC has a very good dynamic response, which also proves the effectiveness and superiority of the MFLC method.

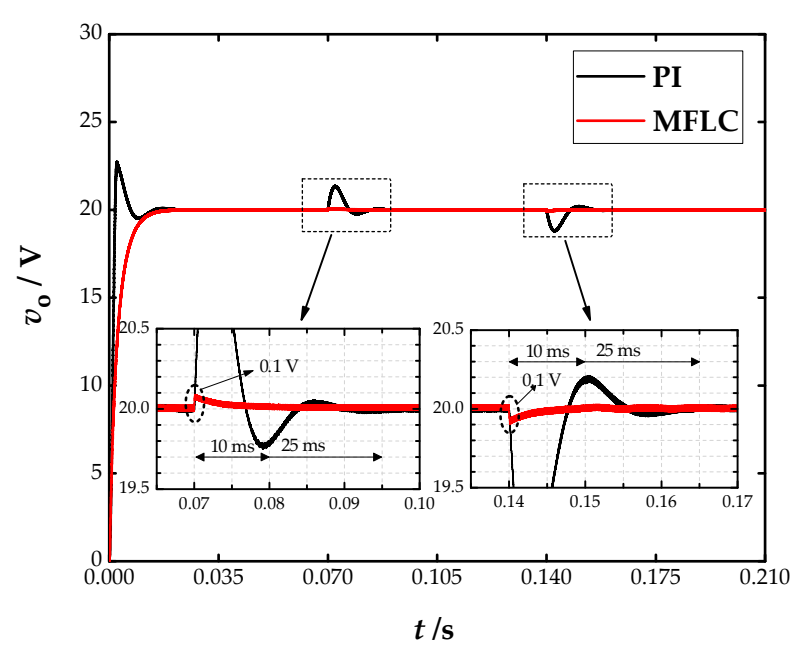

(a)

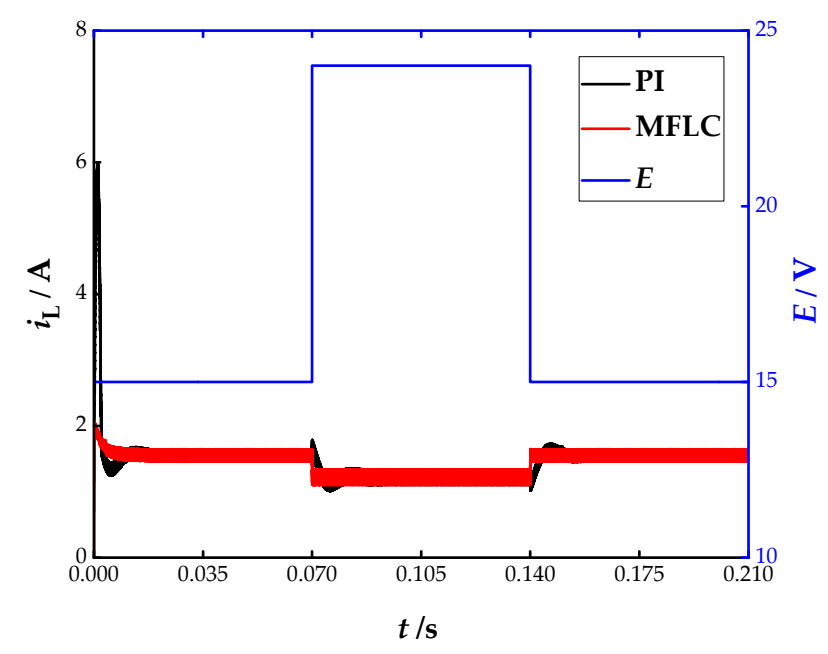

(b)

Figure 5. The response of the buck-boost converter when the input voltage $E$ changes suddenly at 0.07 and $0.14 \mathrm{~s}$, respectively. (a) Response curve of the output voltage $v_{\mathrm{O}} ;$ (b) Response curve of the input current $i_{\mathrm{L}}$.

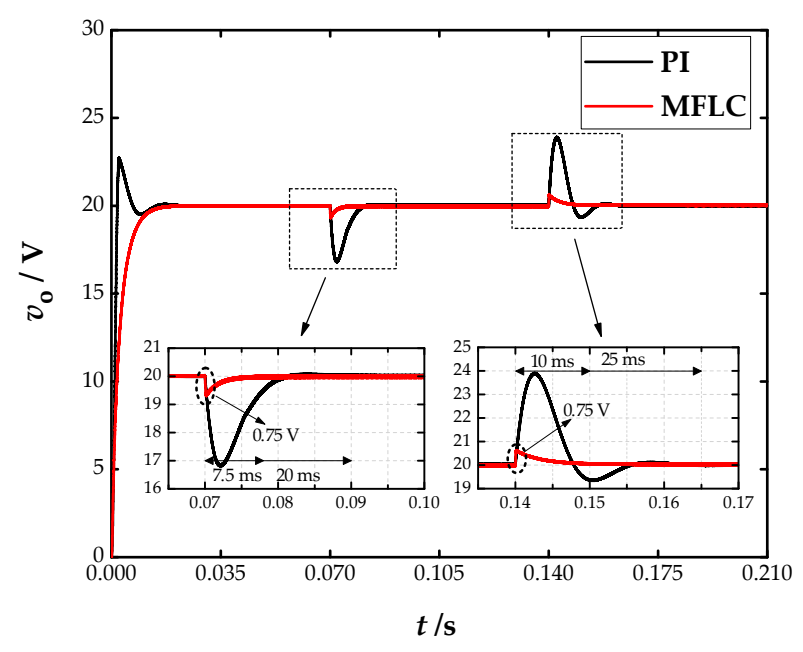

(a)

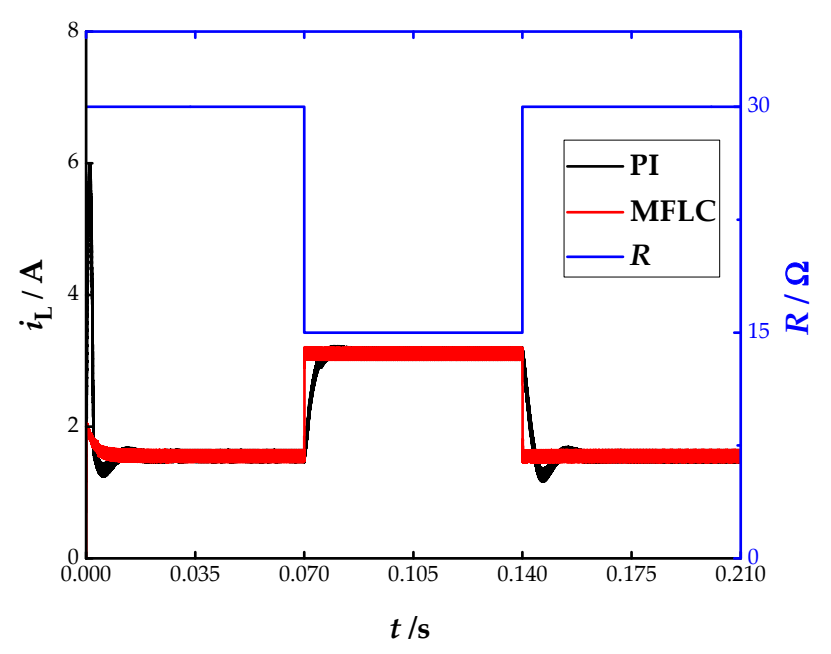

(b)

Figure 6. The response of the buck-boost converter when the load resistance $R$ changes suddenly at 0.07 and $0.14 \mathrm{~s}$, respectively. (a) Response curve of the output voltage $v_{\mathrm{O}} ;(\mathbf{b})$ Response curve of the input current $i_{\mathrm{L}}$.

\subsection{Step Change of the Reference Voltage $v_{\text {or }}$}

Figure 7 shows the response curves of the output voltage and the input current of the buck-boost converter when the reference voltage changes suddenly. At $0.07 \mathrm{~s}$, the reference voltage of the buck-boost converter changes from 20 to $15 \mathrm{~V}$; at $0.14 \mathrm{~s}$, the reference voltage changes from 15 to $20 \mathrm{~V}$. It can be seen from Figure $7 \mathrm{a}$ that when the reference voltage changes step by step, both control methods can make the output voltage accurately track the change of the reference voltage. Under the action of MFLC, the dynamic response process of the output voltage has no overshoot, and the transient time is very short. However, the output voltage under the traditional double closed-loop PI control takes one cycle of oscillation to stabilize at the reference value, and its transient time is long, further proving the superiority of the MFLC method. Figure $7 \mathrm{~b}$ shows the change process of the input 
current, in which the input current under MFLC has a smoother response, and its transient process is far better than that of the traditional double closed-loop PI control.

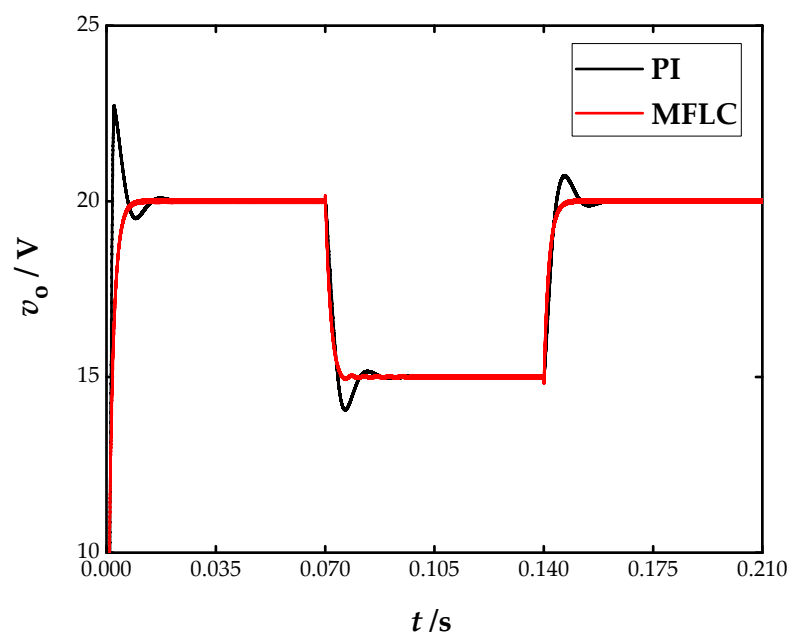

(a)

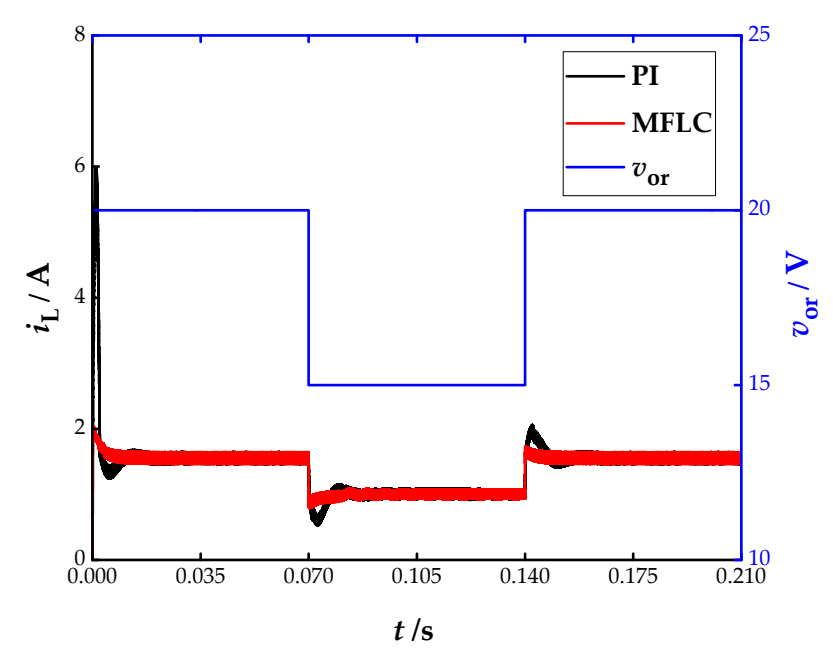

(b)

Figure 7. The response of the buck-boost converter when the reference voltage $v_{\text {or }}$ changes suddenly at 0.07 and $0.14 \mathrm{~s}$, respectively. (a) Response curve of the output voltage $v_{\mathrm{O}} ;(\mathbf{b})$ Response curve of the input current $i_{\mathrm{L}}$.

\section{Conclusions}

In this paper, a multi-index feedback linearization control strategy was used to solve the problem that the controller of the buck-boost converter is difficult to design due to its nonlinear and nonminimum phase characteristics. This method only needs to use a simple linear system control theory to make the controlled system have good performance and a great stability region. This paper analyzed the operation mechanism and parameter adjustment basis of the multi-index feedback linearization control method in the buck-boost converter and designed the corresponding control law. The simulation results show that compared with the traditional double closed-loop PI control, the multi-index feedback linearization control method can make the buck-boost converter, with sudden changes of input voltage, load resistance, and reference voltage, have a better voltage tracking performance, strong robustness, and fast transient response, which fully demonstrates the advantages of the multi-index feedback linearization control method in the controller design of the buck-boost converter. In addition, the proposed method is also applicable to other DC/DC converters, such as Boost and Cuk converters.

Author Contributions: Conceptualization, X.L. and X.C.; methodology, X.L. and X.C.; software, X.C.; validation, X.C.; formal analysis, X.C.; resources, X.L.; data curation, X.C.; writing-original draft preparation, X.L. and X.C.; writing-review and editing, X.L. and X.C.; visualization, X.L.; supervision, X.L.; project administration, X.L.; funding acquisition, X.L. All authors have read and agreed to the published version of the manuscript.

Funding: This research was funded by National Natural Science Foundation of China, grant number 51267001 .

Conflicts of Interest: The authors declare no conflict of interest.

\section{References}

1. Gorji, S.A.; Mostaan, A.; My, H.T.; Ektesabi, M. Non-isolated buck-boost dc-dc converter with quadratic voltage gain ratio. IET Power Electron. 2019, 12, 1425-1433. [CrossRef]

2. Veerachary, M.; Khubchandani, V. Analysis, design, and control of switching capacitor based Buck-boost converter. IEEE Trans. Ind. Appl. 2018, 55, 2845-2857. [CrossRef] 
3. Elamalayil Soman, D.; Leijon, M. Cross-Regulation assessment of DIDO Buck-Boost converter for renewable energy application. Energies 2017, 10, 846. [CrossRef]

4. Sarikhani, A.; Allahverdinejad, B.; Hamzeh, M.; Afjei, E. A continuous input and output current quadratic buck-boost converter with positive output voltage for photovoltaic applications. Sol. Energy 2019, 188, 19-27. [CrossRef]

5. Zhao, B.; Abramovitz, A.; Liu, C.; Yang, Y.; Huangfu, Y. A family of single-stage, buck-boost inverters for photovoltaic applications Energies 2020, 13, 1675. [CrossRef]

6. Jamshidpour, E.; Jovanović, S.; Poure, P. Equivalent Two Switches and Single Switch Buck/Buck-Boost Circuits for Solar Energy Harvesting Systems. Energies 2020, 13, 583. [CrossRef]

7. Ketsingsoi, S.; Kumsuwan, Y. An off-line battery charger based on buck-boost power factor correction converter for plug-in electric vehicles. Energy Procedia 2014, 56, 659-666. [CrossRef]

8. Wu, T.H.; Moo, C.S.; Hou, C.H. A battery power bank with series-connected buck-boost-type battery power modules. Energies 2017, 10, 650. [CrossRef]

9. Liu, S.; Xie, X.; Yang, L. Analysis, modeling and implementation of a switching bi-directional buck-boost converter based on electric vehicle hybrid energy storage for V2G system. IEEE Access 2020, 8, 65868-65879. [CrossRef]

10. Lai, C.M.; Lin, Y.C.; Lee, D. Study and implementation of a two-phase interleaved bidirectional DC/DC converter for vehicle and dc-microgrid systems. Energies 2015, 8, 9969-9991. [CrossRef]

11. Lin, R.L.; Chang, Y.C.; Lee, C.C. Optimal design of LED array for single-loop CCM buck-boost LED driver. IEEE Trans. Ind. Appl. 2013, 49, 761-768. [CrossRef]

12. Teso-Fz-Betoño, D.; Aramendia, I.; Martinez-Rico, J.; Fernandez-Gamiz, U.; Zulueta, E. Piezoelectric Energy Harvesting Controlled with an IGBT H-Bridge and Bidirectional Buck-Boost for Low-Cost 4G Devices. Sensors 2020, 20, 7039. [CrossRef]

13. Chen, Z.; Hu, J.; Gao, W. Closed-loop analysis and control of a non-inverting buck-boost converter. Int. J. Control 2010, 83, 2294-2307. [CrossRef]

14. Chen, J.; Maksimovic, D.; Erickson, R.W. Analysis and design of a low-stress buck-boost converter in universal-input PFC applications. IEEE Trans. Power Electron. 2006, 21, 320-329. [CrossRef]

15. Yuan, L.; Shen, J.Q.; Xiao, F. Modeling and nonlinear phenomena simulation of current-mode controlled Buck-Boost converter. J. Cent. South Univ. 2012, 43, 972-979.

16. Lian, K.Y.; Liou, J.J.; Huang, C.Y. LMI-based integral fuzzy control of DC-DC converters. IEEE Trans. Fuzzy Syst. 2006, 14, 71-80. [CrossRef]

17. Wu, Y.; Huang Fu, Y.J.; Zhang, L.; Zhou, L.W. A robust high order sliding mode for Buck-Boost converters with large disturbances. Proc. CSEE 2015, 35, 1740-1748.

18. Olalla, C.; Leyva, R.; Queinnec, I.; Maksimovic, D. Robust Gain-Scheduled Control of Switched-Mode DC-DC Converters. IEEE Trans. Power Electron. 2012, 27, 3006-3019. [CrossRef]

19. He, R.; Ortega, J.; Machado, J.E.; Li, S. An adaptive passivity-based controller of a buck-boost converter with a constant power load. Asian J. Contr. 2019, 21, 581-595. [CrossRef]

20. Yfoulis, C.; Papadopoulou, S.; Voutetakis, S. Robust Linear Control of Boost and Buck-Boost DC-DC Converters in Micro-Grids with Constant Power Loads. Energies 2020, 13, 4829. [CrossRef]

21. Cavanini, G.; Cimini, G.; Ippoliti, G.; Bemporad, A. Model predictive control for pre-compensated voltage mode controlled DC-DC converters. IET Control Theory Appl. 2017, 11, 2514-2552. [CrossRef]

22. Yfoulis, C.; Papadopoulou, S.; Voutetakis, S. Enhanced control of a buck-boost DC-DC converter via a closed-form MPC reference governor scheme. In Proceedings of the IECON 2019, Lisbon, Portugal, 14-17 October 2019; pp. 201-206.

23. de Jesús Rubio, J. Robust feedback linearization for nonlinear processes control. ISA Trans. 2018, 74, 155-164. [CrossRef]

24. Lu, Q.; Sun, Y.; Mei, S. Nonlinear Control Systems and Power System Dynamics; Springer Science \& Business Media: Berlin/Heidelberg, Germany, 2013.

25. Arora, S.; Balsara, P.; Bhatia, D. Input-output linearization of a boost converter with mixed load (constant voltage load and constant power load). IEEE Trans. Power Electron. 2018, 34, 815-825. [CrossRef]

26. Ai, C.; Gao, W.; Hu, Q.; Zhang, Y.; Chen, L.; Guo, J.; Han, Z. Application of the Feedback Linearization in Maximum Power Point Tracking Control for Hydraulic Wind Turbine. Energies 2020, 13, 1529. [CrossRef]

27. Wang, C.S.; Chiang, M.H. A novel pitch control system of a large wind turbine using two-degree-of-freedom motion control with feedback linearization control. Energies 2016, 9, 791. [CrossRef]

28. Chowdhury, M.A.; Shafiullah, G.M. SSR mitigation of series-compensated DFIG wind farms by a nonlinear damping controller using partial feedback linearization. IEEE Trans. Power Syst. 2017, 33, 2528-2538. [CrossRef]

29. Aghili, F. Optimal feedback linearization control of interior PM synchronous motors subject to time-varying operation conditions minimizing power loss. IEEE Trans. Ind. Electron. 2017, 65, 5414-5421. [CrossRef]

30. Callegaro, L.; Ciobotaru, M.; Pagano, D.J.; Fletcher, J.E. Feedback linearization control in photovoltaic module integrated converters. IEEE Trans. Power Electron. 2018, 34, 6876-6889. [CrossRef]

31. Salimi, M.; Siami, S. Closed-Loop control of DC-DC buck converters based on exact feedback linearization. In Proceedings of the 2015 4th International Conference on Electric Power and Energy Conversion Systems (EPECS) IEEE, Sharjah, United Arab Emirates, 24-26 November 2015; pp. 1-4. 
32. Tawai, A.; Panjapornpon, C. Input-output linearizing control strategy for an ethylene dichloride cracking furnace using a coupled PDE-ODE model. Ind. Eng. Chem. Res. 2016, 55, 683-691. [CrossRef]

33. Panjapornpon, C.; Limpanachaipornkul, P.; Charinpanitkul, T. Control of coupled PDEs-ODEs using input-output linearization: Application to a cracking furnace. Chem. Eng. Sci. 2012, 75, 144-151. [CrossRef]

34. Khan, M.A.; Abid, M.; Ahmed, N.; Wadood, A.; Park, H. Nonlinear Control Design of a Half-Car Model Using Feedback Linearization and an LQR Controller. Appl. Sci. 2020, 10, 3075. [CrossRef]

35. Accetta, A.; Alonge, F.; Cirrincione, M.; Pucci, M.; Sferlazza, A. Feedback linearizing control of induction motor considering magnetic saturation effects. IEEE Trans. Ind. Appl. 2016, 52, 4843-4854. [CrossRef]

36. Navabi, M.; Hosseini, M.R. Spacecraft quaternion based attitude input-output feedback linearization control using reaction wheels. In Proceedings of the 2017 8th International Conference on Recent Advances in Space Technologies (RAST) IEEE, Istanbul, Turkey, 19-22 June 2017; pp. 97-103.

37. Giuseppi, A.; Pietrabissa, A.; Cilione, S.; Galvagni, L. Feedback linearization-based satellite attitude control with a life-support device without communications. Control Eng. Pract. 2019, 90, 221-230. [CrossRef]

38. Li, X.C.; Cheng, S.J.; Wei, H.; Luo, C. Important affection of the output function in SISO nonlinear control system design. Proc. CSEE 2004, 24, 50-56. 